\title{
Comparative assessment for biogenic carbon accounting methods in carbon footprint of products: a review study for construction materials based on forest products
}

\author{
Lars GF Tellnes ${ }^{(1)}$, \\ Christelle Ganne-Chedeville ${ }^{(2)}$, \\ Ana Dias ${ }^{(3)}$, \\ Franz Dolezal ${ }^{(4)}$, \\ Callum Hill ${ }^{(5-6)}$, \\ Edwin Zea Escamilla ${ }^{(7)}$
}

\begin{abstract}
The forest and building sector is of major importance in climate change mitigation and therefore construction materials based on forest products are of great interest. While energy efficiency has had a large focus in climate change mitigation in the building sector, the carbon footprint of the construction material is gaining relevance. The carbon footprint of construction materials can vary greatly from one type to another, the building sector is consequently demanding documentation of the carbon footprint of the materials used. Using an environmental product declaration (EPD) is an objective and standardised solution for communicating the environmental impacts of construction products and especially their carbon footprint. Nevertheless, it is challenging to include the features of forest products as pools of carbon dioxide. There is currently a focus on research into methods for the accounting of sequestered atmospheric carbon dioxide and also implementation of these methods into technical standards. This paper reviews the recent research and technical standards in this field to promote a common understanding and to propose requirements for additional information to be included in EPDs of forest-based products. The main findings show the need for reporting the contribution of biogenic carbon to the total on greenhouse gas emissions and removals over the product's lifecycle. In order to facilitate the implementation of more advanced methods from research, the EPD should also include more detailed information of the wood used, in particular species and origin.
\end{abstract}

Keywords: Climate Change, Forest Based Construction Materials, Environmental Product Declaration (EPD), Carbon Footprint, Global Warming, Delayed Emissions, Carbon Storage, Biogenic Carbon

ronmental performance of construction products (Minkov et al. 2015). This can be related to increasing concerns regarding Greenhouse Gas (GHG) emissions from hu-
There is an increasing use of carbon footprinting and Environmental Product Declaration (EPD) for communicating the envi- man activities and associated climate change (Stechemesser \& Guenther 2012). Product carbon footprint accounts the total amount of GHG emitted during the life cycle of goods and services, based on Life Cycle Assessment (LCA). Thus, this is based on a different approach than the GHG assessments at the level of projects, corporations, nations and individuals which mostly account for direct GHG emissions, not addressing indirect emissions from upstream and downstream activities (Bolwig \& Gibbon 2009). Addressing the accounting of biogenic carbon flows and their relation to the global warming impacts associated with a product is specially challenging for forest products (Sandin et al. 2016). During plant growth, carbon dioxide is removed from the atmosphere by photosynthesis, but can later be partly or fully re-emitted to the atmosphere at different stages of the life cycle. The management of carbon in the biosphere differs from fossil carbon management, in that biogenic carbon is both emitted from and sequestered to the biosphere. Whether there is a net radiative 
forcing, cooling or equilibrium depends on the balance and timing of the release and sequestration of the biogenic carbon (McKechnie et al. 2011, Lippke et al. 2011, Cherubini et al. 2011, Brandão et al. 2013, Helin et al. 2013, Downie et al. 2014). Furthermore, the utilisation of harvested forest products in long-life products also allows for the carbon storage benefits of the material to be extended beyond the forest by delaying the return of carbon to the atmosphere. In fact, the use of forest products in the built environment represents a stable and easily accountable way of storing atmospheric carbon for long periods of time, creating a new option for carbon pools (Moura Costa \& Wilson 2000, Levasseur et al. 2010, Arfvidsson et al. 2013, Vogtländer et al. 2014). The substitution of other construction materials, which often have a higher carbon footprint, brings additional benefits (Gustavsson et al. 2006, ArchilaSantos et al. 2012, Fouquet et al. 2015, Peñaloza et al. 2016, Zea Escamilla et al. 2016) like the protection of the environment and job opportunities.

The question is: how can carbon storage benefit be measured and reported in the calculation of the carbon footprint of products using LCA? Carbon accounting refers to processes used to measure and track the flows of carbon atoms through technological systems and how these interact with the environment. Methodologies for carbon accounting are assuming greater importance due to concerns regarding the impact of the release of fossil carbon into the atmosphere, primarily as carbon dioxide and methane (Stechemesser \& Guenther 2012). Carbon accounting is an essential element of carbon trading schemes, such as the European Union Emissions Trading System. The emission trading scheme sets a limit on total amount of emissions allowed by participating installations in the European Union and then the allowances of emitting GHG can be traded. The aim is to give market incentives for emission mitigations. Carbon accounting is also needed in order to report on national GHG inventories required under the United Nations Framework Convention on Climate Change, Kyoto protocol and Paris Agreement (Cochran 2016). Carbon footprinting of products can also be used as a means of supporting informed decisions about products and processes, using LCA approaches. Conventional LCA methods do not assign any benefits to the temporary storage of atmospheric carbon or delayed emissions, because the timing of emissions relative to removals is not considered. Several LCA evaluation methods have been used to address these temporal aspects of biogenic carbon on global warming (Richards 1997, Fearnside et al. 2000, Moura Costa \& Wilson 2000, Herzog et al. 2003). Brandão et al. (2013) discussed established methods and developing approaches: the Fixed Global Warming Potential (GWP) method (no assignment to temporal aspects), the
Moura Costa method (Moura Costa \& Wilson 2000), the Lashof method (Fearnside et al. 2000), the PAS-2050 method (PAS2050 2008, PAS-2050 2011), the Dynamic LCA method (Levasseur et al. 2010), and the ILCD Handbook method (European Commission 2010). New methods also include forest dynamics and timing of carbon flows (Guest et al. 2013a, Vogtländer et al. 2014, De Rosa et al. 2016), but this implies also a greater need for data in the assessment. All options (except the Fixed GWP method) offer the possibility to consider delayed emissions instead of instantaneous emissions. However, there is currently no consensus for the appropriate methods to be applied neither in scientific literature nor in technical standards (Klein et al. 2015, Peñaloza et al. 2016, Røyne et al. 2016, Sandin et al. 2016, Zea Escamilla et al. 2016). Consequently undertaking LCA and EPDs of construction materials based on forest products remains a challenge for the practitioners. More accuracy and robustness is required in order to support decisions. New methods also include forest dynamics and timing of carbon flows (Guest et al. 2013a, Vogtländer et al. 2014, De Rosa et al. 2016), but this implies also a greater need for data in the assessment.

The objective of this paper is to propose requirements for additional information to be included in EPDs of forest-based products (e.g., bamboo, cork, wood and modified wood products) used in construction that incorporate the emerging methods. This is performed by a systematic comparison of the current methods used for biogenic carbon accounting in carbon footprinting and EPDs of forest-based construction materials. This paper reviews the relevant standards, guidelines, scientific publications, Technical Reports (TR) and Technical Specifications (TS). Furthermore, the identified methods are compared and discussed in relation to the need for more accurate methods that have been expressed by the scientific community. The following research questions are addressed:

- Which data are needed in emerging research methods for climate change modelling of forest products?

-What is required in standards, TR, TS and guidelines for a more complete carbon footprinting of forest products?

- What additional information should be included in carbon footprinting of forest products to facilitate the use of emerging methods?

\section{Data and methods}

\section{Literature review of emerging research methods}

The review includes research methods relevant for dealing with biogenic carbon flows and storage in forest products under the scope of LCA and carbon footprint. We used ISI Web of Knowledge ${ }^{\circledast}$ as well as Google Scholar ${ }^{\circledast}$ for identification of the scientific publications. The literature research was done with the following criteria:

- Peer-review papers in English were selected where the biogenic carbon accounting for forest products used in construction was the main objective and including at least the impact category global warming.

- Published literature on methodologies needed for accounting of carbon flows of biofuels were excluded, as the focus of the paper is the long-term utilisation of forest products in construction.

- Most recent published research methods were considered, starting from 2010.

- Publications were selected when methods were described in detail.

- Former methods (before 2010) were not considered as they are already integrated into standards, or not used in calculations anymore.

\section{Review of technical standards and} systematic comparison

The term technical standards is used as an overall term for international and regional standards, TS, TR, and guidelines which have the purpose of being a formal document giving guidelines and requirements for methods used in carbon footprint of products. This review includes technical standards guidelines that are relevant for LCA, EPD and carbon footprinting with regard to forest products. As EPDs are based on Product Category Rules (PCRs), technical standards focusing on PCRs are also addressed in this review. A PCR is a set of specific rules, requirements and guidelines for developing EPD for one or more product categories (ISO-14025 2010). Technical standards not including any aspect of biogenic carbon are left out of the review. Based on the review of technical standards, the different requirements and methods identified are grouped and compared.

\section{Results}

The section presents the results of the study in three parts: (i) a literature review of emerging methods in research; (ii) a review of technical standards; and (iii) a systematic comparison of the technical standards.

\section{Literature review of emerging research methods}

Four recent methods for dealing with biogenic carbon were found in research literature and are presented here.

\section{Dynamic Life Cycle Assessment}

The methodology developed in Levasseur et al. (2010) and applied in Levasseur et al. (2013), proposes the inclusion of time series in the LCA calculations. This is defined by the authors as a dynamic LCA. This approach uses the temporal profile of $\mathrm{GHC}$ emissions and then to estimate the impact of those emissions, it uses time-dependent 
characterisation factors for the global warming impact category for any given time horizon that are based on the concept of cumulative radiative forcing of GHG emissions. The inclusion of time series allows the inclusion of capture, storage, delayed and avoided emissions on the LCA of bio-based products. The dynamic LCA approach combines instantaneous and cumulative impacts on the GWP category within a defined time horizon. For this calculation, the approach first defines the dynamic characterisation factor in terms of instantaneous radiative forcing per unit mass increase in the atmosphere; the atmospheric load of the given GHG within the period. A specific characterisation factor is calculated for each type of GHG emission. This factor is used then to characterise the impact results for the specific time and GHG emission. The sum of the characterised impacts is considered as the instantaneous GWP. Consequently, the sum of all global warming instantaneous impacts is considered as the cumulative global warming impact for the defined time horizon. One of the main advantages of this approach is that it accounts for the emissions related to products with extended chains of production, like timber and other bio-based products. The ability to determine the GWP at different time horizons allows a better allocation of the emissions through the different life cycle stages of products.

\section{Approach based on the global carbon cycle}

The approach proposed by Vogtländer et al. (2014) considers the issues related to temporal carbon storage in timber products. These authors argue that the 100-year period used in PAS-2050 (2008) and the ILCD handbook (European Commission 2010) for accounting GHG emissions is an arbitrary choice. Besides, they point out that there is no need for use of a time frame when preparing the Life Cycle Inventory (LCl), since this is a straightforward calculation of mass and energy flows. However, when using single indicator systems in the Life Cycle Impact Assessment (LCIA) phase, time horizons have to be considered. The calculation method integrates the time-related storage of carbon, causing a temporary reduction in radiative forcing, in forest products LCA. The authors have observed that PAS-2050 and the International Reference Lifecycle Database (ILCD) Handbook specification do not fulfil the baseline LCA methodology. Vogtländer et al. (2014) state that the "optional method" of the ILCD Handbook and PAS-2050 overestimate the benefits of temporary fixation of biogenic $\mathrm{CO}_{2}$. This overestimation is due to the linear discounting of the delayed $\mathrm{CO}_{2}$ pulses in contrast to the non-linear Lashof calculations for the decay of $\mathrm{CO}_{2}$ pulses in the atmosphere modelled by the Bern cycle (Fearnside et al. 2000). The new proposed method integrates the global carbon-cycle and land use change. The meth-

Tab. 1 - Data needed for each emerging research method for biogenic carbon accounting. $(*)$ : Yes, but reference values are available.

\begin{tabular}{|c|c|c|c|c|}
\hline Data needed & 亗 & 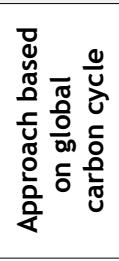 & 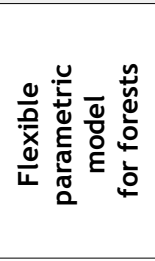 & 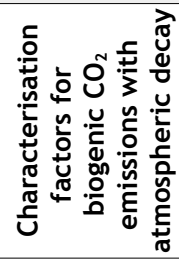 \\
\hline Wood species & No & No & Yes & No \\
\hline Rotation time & Yes & No & Yes & Yes \\
\hline $\begin{array}{l}\text { forestry practice (sustainable } \\
\text { or not) }\end{array}$ & Yes & No & No & No \\
\hline Biomass annual increment & Yes & Yes & Yes & No \\
\hline $\begin{array}{l}\text { Biogenic carbon emissions per } \\
\text { year over complete life cycle }\end{array}$ & Yes & Yes & No & Yes \\
\hline $\begin{array}{l}\text { Biogenic carbon removals per } \\
\text { year over complete life cycle }\end{array}$ & Yes & No & No & Yes \\
\hline Basic wood density & Yes & No & Yes & No \\
\hline Carbon content of wood & Yes & Yes & Yes & No \\
\hline $\begin{array}{l}\text { Ratio below-ground/ above- } \\
\text { ground biomass }\end{array}$ & Yes & Yes & Yes* & No \\
\hline $\begin{array}{l}\text { Biomass conversion and } \\
\text { expansion factor }\end{array}$ & No & No & Yes* $^{*}$ & No \\
\hline $\begin{array}{l}\text { Share of above ground and } \\
\text { below-ground slashes }\end{array}$ & No & Yes & Yes* & No \\
\hline Percent woody debris harvested & No & No & Yes* & No \\
\hline
\end{tabular}

od is based on the argument that carbon sequestration can only be a benefit in the case of a global growth of forest area and a simultaneous growth of wood utilisation in construction. The method is divided into 5 steps: (1) calculation of the relationship of carbon stored in the forest and carbon stored in end-products; (2) calculation of land-use change correction factors following the Intergovernmental Panel on Climate Change (IPCC) standards; (3) calculation of extra-growth of forest carbon content due to market growth; (4) calculation of extra stored carbon in construction due to increased utilisation (following Publicly Available Specification PAS-2050 and ILCD Handbook); (5) final calculation of sequestered carbon by multiplying steps 1,2 and 3 plus step 4. For validation, the methodology was applied to European softwood and Chinese bamboo. In this approach there is no need for a discounting system for delayed emissions, but it requires accurate information on land transformation processes.

\section{Flexible parametric model for forests}

De Rosa et al. (2016) propose a simplified method to model the time-dependent carbon flows of forests. The goal is to provide a practical tool to understand the $\mathrm{LCl}$ of forest flows in the context of the typical lack of data encountered by LCA practitioners. In the scope, it is explicitly stated that the method only considers the boundaries of the forest and not the product, so the effect of time of carbon storage in forest products cannot be accounted with this method. The method offers a model based on 4 choices: (1) the type of carbon pool (above-ground and below-ground, only above-ground or only carbon in stem); (2) the dynamics of the biomass growth (sigmoidal or linear dynamic); (3) the dynamic of the biomass decomposition aboveground and below-ground (sigmoidal, negative exponential or linear dynamic); and (4) the forest management features (stand type, rotation time, thinning frequency and intensity). The method was validated with spruce using the more complex and recognised method CO2FIX (Masera et al. 2003), to cope with spatial and temporal carbon flow accounting for a more accurate GWP calculation of forest products.

\section{Characterisation factors for biogenic $\mathrm{CO}_{2}$} emissions with atmospheric decay

The $\mathrm{GWP}_{\text {bio }}$ methods was first presented by Cherubini et al. (2011) with the introduction of characterisation factors for biomass combustion dependent on the number of years needed for regrowth of the biomass. The method for estimating GWP from biomass thus include the temporary effect carbon dioxide in the atmosphere have on climate change until being captured by biomass regrowth. Guest et al. (2013b) extended these lists of characterisation factors to also include the service life of a biomass product used for energy at the endof-life. The method was initially used to assess the use of bioenergy, but has been also recently applied for assessment of construction materials (Tellnes et al. 2014, Nordby et al. 2015). The data needed for applying these methods are the rotation times of the biomass used for energy 
throughout the life cycle and the amount of biogenic carbon dioxide emission from combustion of the biomass.

\section{Data needed for the emerging methods}

The data needed for applying the emerg ing research methods in this review are presented in Tab. 1. None of the 12 parameters are needed by all of the methods. The method for calculating $\mathrm{GWP}_{\text {bio }}$ requires fewest data with only three of the $12 \mathrm{pa}$ rameters. The most amount of parameters are needed by the method for flexible parametric model for forest with nine parameters, but have reference values for four of them.

\section{Review of technical standards}

There are many technical standards for LCA and carbon footprint available and the one relevant to forest based building materials and biogenic carbon are reviewed. These can be separated into those dealing with only building materials (ISO-21930, EN15804, CEN/TR-16970, EN-16485) and those which covers all products (PAS-2050, ISO/ TS-14067, PEF). Another distinction is the geographic coverage, where some are in ternational standards (ISO-21930, PAS2050, ISO/TS-14067), while others are European specific (EN-15804, CEN/TR-16970, EN16485, PEF) and which would have stronger links to government regulation. These are explained separately in this section and key issues in comparison in the next section.

\section{ISO/DIS-21930 (2015): Sustainability in building and civil engineering works - Environmental declaration of building products}

The ISO-21930 (2007) was the first standard for LCA and EPD specifically for build ing materials. The ISO/DIS-21930 (2015) is a revision of the ISO-21930 (2007), but with a strong influence of the content in EN15804 (2013). While ISO-21930 (2007) did not mention biogenic carbon, ISO/DIS21930 (2015) has included specific requirements mainly based on the specifications in ISO/TS-14067 (2013). This includes consideration that biogenic carbon uptake and emissions have an impact on the GWP. For wood from sustainably managed forests, the draft standard states that zero emissions concerning land use change can be assumed. In addition, credits for delayed emissions can only be separately included under a so-called category "Additional environmental information not derived from LCA".

\section{EN-15804 (2012): Sustainability of} construction works - Environmental product declarations - Core rules for the product category of construction products

The EN-15804 (2012) provides horizontal core PCR for all construction products and services to ensure that all EPDs for these products and services are calculated, verified and presented in a harmonised way.
The standard is a part of CEN/TC 350 group of standards developed for sustainability assessments of buildings. Hence, the purpose is to assess the buildings as an end product and materials are interim products where the performance can only be evaluated in a building context. EN-15804 standard describes, among other aspects, which stages and processes of the product's life cycle shall be considered, the information to be declared and the way in which it is compiled and reported, and the LCIA method to be applied. According to this standard, the global warming impact category should be included in the EPDs and the GWPs should be those applied in the LCIA characterisation factors from the ILCD provided by the European Commission and respective updates (European Commission 2010). The ILCD characterisation factors published include biogenic carbon flows with impacts on global warming. However, EN-15804 does not provide specific rules on how to calculate biogenic carbon emissions and removals on the GWP indicator. The standard however does specify how to deal with biogenic carbon in co-product allocation so that it follows the amount of carbon inherent in the material.

\section{EN-15804 (2012)+A1:2013: Sustainability of} construction works - Environmental product declarations - Core rules for the product category of construction products The EN-15804:2012+A1:2013 (EN-15804 $2013)$ is an updated version of the EN-15804 (2012) and has the same goals. As in the previous version, global warming is an impact category that should be included in the EPDs but, in this case, GWPs should be those specified in the impact assessment methodology CML-IA version 4.1 (UL-IES 2012). However, neither the standard, nor the LCIA method provides specific rules on how to calculate biogenic carbon emissions and removals.

\section{CEN/TR-16970 (2016): Sustainability of construction works. Guidance for the implementation of EN 15804}

As some rules set in EN-15804 are defined in a very general way, the CEN/TR-16970 (2016) complements EN-15804 by giving guidance and further explanation for its implementation, including how biogenic carbon should be treated. According to this document, the flows of biogenic carbon should be reported separately in the $\mathrm{LCl}$. When biogenic carbon is transformed to emissions other than $\mathrm{CO}_{2}$ (e.g., methane, $\mathrm{CH}_{4}$ ) the emissions should also be accounted for in the $\mathrm{LCl}$ and evaluated in the LCIA. The removal of $\mathrm{CO}_{2}$ from the atmosphere is characterised with $-1 \mathrm{~kg} \mathrm{CO} \mathrm{CO}_{2} / \mathrm{kg}$ $\mathrm{CO}_{2}$ for biomass coming from sustainably managed sources as it represents carbon sequestration. According to CEN/TR-16970 (2016), the concept of sustainably managed forests is described as linked, but not limited, to forest certification schemes. Other evidence such as national reporting under the United Nations Framework Convention on Climate Change can be used to identify forests for which stable or increasing forest carbon stocks can be assumed. For non-sustainably managed sources, a conservative approach is applied, e.g., by assuming that the biogenic carbon uptake is characterised with o $\mathrm{kg} \mathrm{CO}$ eq $/ \mathrm{kg} \mathrm{CO}$. A characterisation factor of $-1 \mathrm{~kg} \mathrm{CO}$ eq $/ \mathrm{kg}$ $\mathrm{CO}_{2}$ is also assigned to biogenic carbon contained in any secondary fuel or secondary material imported to the product system. Emissions of biogenic $\mathrm{CO}_{2}$ and export of biogenic carbon contained in materials leaving the product system at the endof-waste state are characterised with $+1 \mathrm{~kg}$ $\mathrm{CO}_{2}$ eq $/ \mathrm{kg} \mathrm{CO}$. In addition, the document highlights that the flows of biogenic carbon expressed in $\mathrm{CO}_{2}$ in bio-based materials coming from sustainably managed sources, imported as secondary fuels or materials that are reused, recycled or combusted at the end-of-life scenario will result in zero net contribution to the global warming impact category, when the impact is added up over the whole life cycle, except for the part of biogenic carbon that is converted to $\mathrm{CH}_{4}$ or other $\mathrm{GHG}$ emissions over the life cycle. This assumption is also valid for the flows of biogenic carbon, expressed in $\mathrm{CO}_{2}$, in bio-based materials imported as secondary fuels or materials that are reused, recycled or combusted at the end-of-life scenario.

EN 16485 (2014): Round and sawn timber Environmental Product Declarations Product category rules for wood and wood-based products for use in construction

The EN-16485 (2014) also complements the core PCR established in EN-15804 by providing more specific rules for EPDs of wood and wood-based products used in construction. As the calculation and reporting of biogenic carbon fluxes and impacts are particularly important for wood and wood-based products, this is one of the topics addressed in more detail by this standard. As in CEN/TR-16970 (2016), the fluxes of biogenic carbon expressed in $\mathrm{CO}_{2}$ eq shall be inventoried and documented separately from fossil carbon fluxes. The characterisation factors for biogenic $\mathrm{CO}_{2}$ are also the same as in CEN/TR16970 (2016), but in this standard, there is a different concept of a sustainably managed forest. Thus, the removal of $\mathrm{CO}_{2}$ from the atmosphere by forests is characterised with $-1 \mathrm{~kg} \mathrm{CO}$ eq $/ \mathrm{kg} \mathrm{CO}$ only for forests in countries that have decided to account for the article 3.4 of the Kyoto Protocol (e.g., additional human-induced activities from management of existing forests) or to forests that are operating under established certification schemes for sustainable forest management. The calculation of the amount of biogenic carbon stored in wood and wood-based products should follow the calculation method provided in EN16449 (2014). Besides, EN-16485 (2014) al- 
lows the consideration of the effect of timing of GHG emissions due to biogenic carbon storage as additional environmental information, for example on the basis of PAS-2050 or ILCD method.

\section{PAS-2050 (2011): Specification for the assessment of the life cycle greenhouse gas emissions of goods and services}

The PAS-2050 (2011) gives guidance for the accounting of GHG emissions to and removals from the atmosphere for the assessment of overall GHG emissions in the United Kingdom. The specification refers to the latest IPCC GWP 100 coefficients (assessment period), listed in Annex A of PAS2050. In chapter 5.5 Carbon storage, it is stated that removed carbon, not emitted to the atmosphere within the 100-year assessment period, shall be treated as stored carbon. For products with a shorter life span and so-called "delayed emissions", weighting factors can be calculated. The methodology of this calculation described in Annex $\mathrm{E}$ distinguishes between single delayed release and general cases where timing of releases is averaged. According to a remark given in the same chapter, the use of a weighting factor is no requirement of this PAS. However, for those who wish to undertake this assessment, provision is made in Annex $\mathrm{E}$.

In case carbon storage is included in a GHG assessment, the data source and the carbon storage profile shall be recorded. For the calculation of the weighting factor, emissions arising more than one year up to 25 years after formation of the product shall be taken into account. The calculation of delayed emissions represents a simplification of the IPCC approach. However, effects of delayed emissions can only be applied for biogenic carbon, since stored $\mathrm{CO}_{2}$ has to be removed from the atmosphere before the product is created. Moreover, a prerequisite is that the product must be derived from sustainably managed forests. Otherwise, land use change would have occurred and native forests would have been used.

For a delayed single release of GHG emissions within 25 years, a simple equation is given, taking the number of years between formation of the product and the release of the emissions into account. A different equation is provided for GHG emissions arising over several years. In that case, the weighted average impact is provided.

ISO/TS-14067 (2013): Greenhouse gases -

Carbon footprint of products -

Requirements and guidelines for quantification and communication

This TS gives guidelines for the quantification of GHG emissions and removals. The TS builds largely on existing ISO standard for LCA (ISO-14040/44) and EPD (ISO-14025 2010). Aspects such as land use change, soil carbon, carbon storage in products and other GHG specific requirements was not specified in the existing standards and thus this is an important part of the ISO/TS14067. During development, it was revised several times since conflicting interests of different stakeholders hindered a satisfying compromise. Finally, the original goal of an ISO standard was reduced to a TS. Two different scenarios for the assessment of GHG emissions are suggested. In both scenarios, calculation starts with the moment the product has been brought into use. The first scenario concerns emissions and removals arising from the use stage or end of life stage within 10 years. In this case, emissions and removals are calculated as released or removed at the beginning of the assessment without a timing effect. In the second scenario, for emissions and removals more than 10 years after the product has been brought into use, these emissions and removals have to be included in the carbon footprint, without the effect of timing as well. Nevertheless, a timing effect may also be included and documented separately with specification of the methodology used and the reason why this has been used.

\section{Guidance and requirements for biogenic carbon modelling in PEFCRs. Version 2.2 - February 2016}

The European Commission is developing an approach similar to EPD called Product Environmental Footprint (PEF) and the goal is a single market for green products. PEF covers all kind of products with a common LCA guidance (European Commission 2010), but also with product environmental footprint category rules (PEFCR) and which has been developed for some pilot product groups. De Schryver et al. (2016) provide guidance and requirements for biogenic carbon modelling when developing and implementing PEFCR. The guideline indicates that in the impact categories, credit for delayed emissions shall not be considered, but can be included as "additional environmental information". The impact category for "climate change" was also specified to cover three sub-indicators: (i) Climate change - fossil; (ii) Climate change - biogenic; (iii) Climate change - land use and land transformation.

These shall always be reported as total climate change, which is the sum of the three sub-indicators. When "biogenic" and "land use and land transformation" contributes each to more than $5 \%$ of the total score, these shall also be reported.

There are also two options for modelling biogenic carbon. In option 1 all biogenic carbon uptake and releases are modelled. In option 2 a simplified approach can be used, where only biogenic $\mathrm{CH}_{4}$ emissions are modelled.

\section{Systematic comparison}

Each methodological aspect for accounting of biogenic carbon in carbon footprinting and EPDs are here addressed separately and summarised in Tab. 2. The simplest approach to deal with biogenic car- bon is assuming climate neutrality based on the assumption that $\mathrm{CO}_{2}$ sequestration from biomass growth is equal to $\mathrm{CO}_{2}$ emissions over the full life cycle. This does not include the effects of timing and possible differences between sequestration and emissions. In the review of LCA's, this has been found to be by far the most common chosen approach (Røyne et al. 2016). In the PEF guidelines, this is described as a simplified approach, but which can address a permanent sink when relevant. In PAS2050 and ISO-14067, for short-lived products, like food, biogenic carbon can be left out, but it is to be included for long-lived products. This approach has also been used in the LCA software SimaPro since November 2009 for the implementation of LCA evaluation methods. However, in the last SimaPro update (version 8.2.0.0), methods which specify that biogenic carbon shall be included have now also been implemented. These methods are the ILCD method and the GHG Protocol method (PRé Consultants 2016). As noted earlier, ISO-21930 (2007) and EN-15804 (2012)+ A1:2103 do not specify how to deal with biogenic carbon. The first version of EN15804 (2012) did however require that the last version of the ILCD methods was to be used, which implies that biogenic carbon is to be included. There is a lack of common terminology for this approach in standards and research. In IPCC methods for harvested wood products, the term "instant oxidation" is used when biogenic carbon in products is accounted as an emission at the time of harvest and thus no storage in products are accounted for (IPCC 2014). This follows the same approach as leaving out biogenic carbon in LCA when one assumes that the forest carbon pools are stable. In both LCA and national GHG inventories, this approach requires that a different characterisation factor is used for biogenic methane than for fossil methane in order to adjust for the already accounted emission of biogenic carbon dioxide (Muñoz \& Schmidt 2016). "Instant oxidation" of biogenic carbon is used here as a common term for the approach in both national GHG inventory and LCA.

During manufacturing of materials containing biogenic carbon, transformation processes often lead to several products and co-products where some kind of allocation method is needed. If economic allocation is applied, the input of biomass raw material will not be the same as the amount of biomass in the final product. Hence, several standards require that, when such allocation is used, economic allocation shall not be applied to biogenic carbon.

The biogenic carbon flows can be accounted as removal of carbon dioxide from the atmosphere during plant growth with negative impacts on the climate impacts of the considered life cycle stage. The term "negative impacts" means that there is a reduction in overall radiative forcing be- 
Tab. 2 - Summary of methodological aspects related to biogenic carbon accounting in technical standards for carbon footprint of products and EPDs.

\begin{tabular}{|c|c|c|c|c|c|c|c|c|}
\hline Criteria & 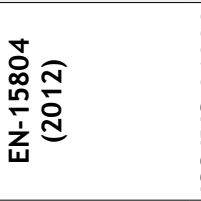 & 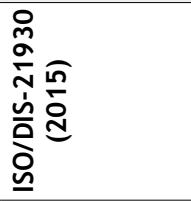 & 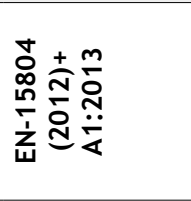 & 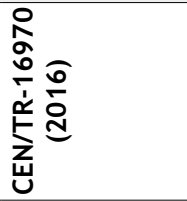 & 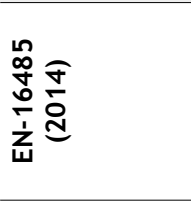 & 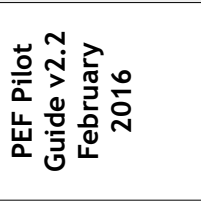 & 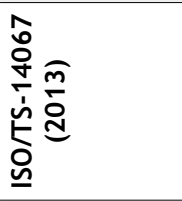 & 员 \\
\hline $\begin{array}{l}\text { Instant } \\
\text { oxidation } \\
\text { allowed }\end{array}$ & Not specified & Not specified & Not specified & Not specified & Not specified & Yes & $\begin{array}{l}\text { Compulsory for } \\
\text { emissions less } \\
\text { than } 10 \text { years }\end{array}$ & For food \\
\hline $\begin{array}{l}\text { Consider } \\
\text { biogenic carbon } \\
\text { flows on GWP }\end{array}$ & $\begin{array}{l}\text { Not directly, but } \\
\text { by reference to } \\
\text { ILCD method }\end{array}$ & Yes & Not specified & Yes & Yes & Yes & Yes & Yes \\
\hline $\begin{array}{l}\text { Modular } \\
\text { approach to } \\
\text { emissions } \\
\text { required }\end{array}$ & Yes & Yes & Yes & Yes & Yes & No & Yes & Not specified \\
\hline $\begin{array}{l}\text { Criteria for } \\
\text { separate } \\
\text { biogenic carbon } \\
\text { flows in } \\
\text { inventory }\end{array}$ & Not specified & Yes & Not specified & Yes & Yes & Yes & Yes & Not specified \\
\hline $\begin{array}{l}\text { Considers } \\
\text { sustainable } \\
\text { harvest of } \\
\text { biomass }\end{array}$ & Not specified & Yes & Not specified & Yes & Yes & - & $\begin{array}{l}\text { Yes, } \\
\text { but with land } \\
\text { use change }\end{array}$ & Not specified \\
\hline $\begin{array}{l}\text { Possible to } \\
\text { include effect } \\
\text { of delayed } \\
\text { emissions on } \\
\text { GWP }\end{array}$ & Not specified & No & Not specified & Not specified & No & No & No & No \\
\hline $\begin{array}{l}\text { Possible to } \\
\text { include effect } \\
\text { of delayed } \\
\text { emissions } \\
\text { separately }\end{array}$ & Not specified & Yes & Not specified & Not specified & Yes & Yes & Yes & Yes \\
\hline $\begin{array}{l}\text { Land use } \\
\text { change }\end{array}$ & Not specified & $\begin{array}{l}\text { Separate, when } \\
\text { significant }\end{array}$ & Not specified & $\begin{array}{l}\text { Yes, with im- } \\
\text { pacts on GWP } \\
\text { or separate? }\end{array}$ & $\begin{array}{l}\text { Yes, } \\
\text { but separate }\end{array}$ & $\begin{array}{l}\text { Yes, } \\
\text { but separate }\end{array}$ & Yes & Yes, on GWP \\
\hline $\begin{array}{l}\text { Soil organic } \\
\text { carbon }\end{array}$ & Not specified & Not specified & Not specified & Not specified & $\begin{array}{l}\text { Yes, but in land } \\
\text { use change }\end{array}$ & $\begin{array}{l}\text { Yes, but in land } \\
\text { transformation. } \\
\text { Soil carbon } \\
\text { uptake excluded }\end{array}$ & $\begin{array}{l}\text { Yes, but within } \\
\text { land use } \\
\text { change. } \\
\text { Ongoing } \\
\text { research is } \\
\text { pointed out }\end{array}$ & $\begin{array}{l}\text { No soil carbon } \\
\text { change }\end{array}$ \\
\hline $\begin{array}{l}\text { Requires } \\
\text { additional } \\
\text { information } \\
\text { relevant to } \\
\text { biogenic carbon }\end{array}$ & Not specified & $\begin{array}{l}\text { Biogenic carbon } \\
\text { in materials } \\
\text { leaving the } \\
\text { product system } \\
\text { as technical } \\
\text { scenario } \\
\text { information }\end{array}$ & Not specified & Not specified & $\begin{array}{l}\text { Apparent } \\
\text { density and } \\
\text { moisture } \\
\text { content of } \\
\text { wood, amount } \\
\text { of biogenic } \\
\text { carbon stored }\end{array}$ & - & Not specified & $\begin{array}{l}\text { Use phase } \\
\text { removals and } \\
\text { emissions } \\
\text { included shall } \\
\text { be recorded, } \\
\text { carbon storage, } \\
\text { land use change }\end{array}$ \\
\hline
\end{tabular}

cause of the removal of atmospheric carbon dioxide. This is reported as negative carbon dioxide equivalents. If the biogenic carbon is later emitted to the atmosphere, it will have a positive impact on the climate change indicator (an increase in radiative forcing). This is reported as positive carbon dioxide equivalents. EN-16485 (2014) includes these accounting rules, but also defines that for wood from sustainable forestry, the effect on GWP over the life cycle is neutral. The approach is based on the modularity principle in EN-15804 (2013), which states that environmental emissions and impacts shall be declared in the life cycle module where they occur. The PAS2050, ISO/TS-14067 and PEF also includes biogenic carbon, but with some specifications. This approach is consistent with the Kyoto II protocol on how biogenic carbon can be accounted for harvested wood products. Some standards require a modular approach for declaring impacts over the life cycle. Hence, the emissions during endof-life shall be declared in the end-of-life module. The modular approach in combination with service life provides a simplified solution for addressing timing of emission throughout the life cycle of products. Consequently, this information is a crucial consideration if emerging methods are to be applied. In mainstream LCA studies, it is often easy to make mistakes in mass balances of the $\mathrm{LCl}$ and, if done with biogenic carbon calculations, this can have a large influence on the results. That is the reason why, several standards require that the biogenic carbon flows are inventoried separately from other carbon dioxide flows. If forests are harvested and no regrowth happens, there will be a permanent change of that area, commonly known as direct land use change or land transformation. For this, several standards requires that direct land use change are included in the calculations of GWP. There are also specific requirements given for instance in $\mathrm{EN}$ 16485 (2014) for when a forestry management practice is considered as sustainable. Under sustainable forest management, the total carbon pools can be assumed as sta- 
ble or increasing, even with local variations occurring. Harvesting and a temporary decrease in the carbon pool in one site is then considered as compensated by the increase of carbon pools on other sites.

If the emission from biogenic carbon or other carbon takes place a long time into the future, this will have a lower impact on GWP than the same emissions today. This was first considered in the calculations in PAS-2050 (2008), but in the second version PAS-2050 (2011) was only allowed as additional information. This approach adjusts the emissions of biogenic or all GHG emissions with regards to time. The characterisation factors are then lower in the future. However, since there is a lack of consensus for these methods, standards that are more recent require that this can only be included as additional information. The most common methods are from PAS-2050 and a simplified version of PAS-2050 in the ILCD method. If the biogenic carbon is not released into the atmosphere within a given time, several standards allow that the carbon dioxide sequestered during plant growth is not released and is accounted with a negative contribution. This can be relevant for long-lived products, landfill, and carbon capture and storage.

Growth of biomass usually affects not only the amount of biogenic carbon in the product harvested, but also in soil, aboveground and below-ground biogenic carbon in forests or agricultural land. These can be defined as part of forest carbon pools as defined by IPCC (2006, cited in EN-16485 2014). The different standards have requirements concerning what kind of information is to be communicated either in a report or in a declaration. This ensures transparency of the calculation and can facilitate the use of other calculation approaches. Carbon footprint can also include the aspects of timing of the growth of biomass in addition to the timing of the emission. No standards comply with this at the moment, but this has been highlighted in several research studies addressed in this research literature review.

\section{Discussion}

This section compiles the main findings in the results and discuss them in relation to the research questions of the study. First discussing the data needed on emerging methods and then secondly the data required by the technical standards for EPD. Lastly, these findings answers to what should be required in future developments of technical standards (Tab. 2).

\section{Data needs for emerging methods for biogenic carbon}

What is common for most methods is that they include rotation periods and flows from and to the atmosphere at the time the emissions occur. There are however, some differences if only the carbon contained in the harvested stem is included or if other pools like below-ground carbon are included. Levasseur et al. (2013) requires the inventory result (sum of the positive and negative emissions) of the given GHG for each year (in $\mathrm{kg}$ ) for the time horizon.

\section{Data and information required in \\ technical standards}

The data and information required in technical standards are not consistent and this shows a need for further work on this subject. EN-16485 (2014) for instance requires apparent wood densities and moisture contents to be included, while others like the ISO/TS-14067 (2013), provides a framework to separate results between biogenic and other GHG emissions. The most recent proposal in ISO/DIS-21930 (2015) is that there is an additional LCl parameter for uptake and emissions for biogenic carbon as carbon dioxide for each module. This will make it possible to adjust the results for not including the biogenic carbon and thus enough for the most standardised methods for carbon footprint. However, none of the standards requires sufficient product information declarations or reports that facilitate a LCA-practitioner to apply the emerging research methods dealing with biogenic carbon on GWP in comparative or whole-building assessment.

\section{Additional needs for parameters and information in EPD}

The methods of dynamically assessing carbon flows of forests based on information in an EPD for a forest product is dependent on the availability of sufficient information in the EPD additionally to what is currently required. This information however has to be possible to obtain for companies and LCA practitioners with a reasonable effort. It also has to be concise so that it will not take up unnecessary space in an EPD. This information and parameters should be sufficient in order to calculate:

- biogenic emissions from biomass within life cycle modules;

- rotation period of the biomass;

- growth state of the harvested forests on national level.

\section{Separate uptake and emissions of each} module

The ISO/DIS-21930 (2015) proposal for having a $\mathrm{LCl}$ indicator for "uptake and emissions associated with biogenic carbon content of the biobased product" and the same for the packaging, should be separated between uptake and emissions and specify that it should be limited to the foreground inventory. This foreground inventory should however include all uptake and emissions from cradle-to-gate. The use of separate uptake and emissions from the foreground also implies that the biogenic carbon not only should be separated from other emissions, but that the background system should be separated from the foreground system. The dynamic LCA method also separates the impacts of biogenic car- bon dioxide and methane (Levasseur et al. 2013). ISO/TS-14067 (2013) provide an approach to separate these in the results and could be used as a reference.

\section{Biomass species and origin}

The species of wood or other biomass will contribute to the estimation of the rotation period. For wood, dividing into softwood and hardwoods would not be sufficient as the parameters for instance in Guest et al. (2013b) requires further specification.

The country or region of origin in combination with the species will enable an estimation of rotation period. In addition, it will also contribute to product specific information necessary to obtain data on the state of national forest inventories. Both species and origin are required to be documented by companies trading timber in the EUTR (EU 2010). For consistency and simplification, the required documentation should therefore be based on the same practice as in EUTR.

\section{Conclusions}

The results of this research highlight the need for more sophisticated modelling of biogenic carbon in LCA, but the different approaches give different results and can be time consuming. Also, there is currently no scientific consensus on which method is the most appropriate for use LCA applied in EPD. The results of the review of technical standards shows that there are difference between those for all products and those covering construction materials. For many products, they are final and the end use is given, in addition to a short lifetime. Construction materials, however, are only intermediate products and the construction is the final product with a long service life. For assessing construction materials based on forest products, the product footprint is often further used as data for construction level assessments. For these reasons modularity in results are important so that adjustments can be made to the specific construction case. In these cases, LCA commissioners might demand that biogenic carbon is assessed with the more sophisticated methods and therefore EPD and PEF should include information facilitating this. In addition to the requirements of EN-16485 (2014) and ISO/DIS-21930 (2015), the removals and emission of each module should be included. The species and the origin of the wood used should also be included in the EPD following the EUTR practice. This review of technical standards and research also shows that there are multiple terms used to address same aspects and harmonisation is needed for a consistent implementation of the methods in future standardisation.

\section{List of abbreviations}

The following abbreviations have been used throughout the manuscript:

- CEN: European Committee for Standardis- 
ation;

- CML-IA: Centre of Environmental Science of Leiden University - Impact assessment method;

- DIS: Draft international standard;

- EN: European Standard;

- EPD: Environmental product declaration;

- EUTR: European Union Timber Regulation;

- GHG: Greenhouse gas;

- GWP: Global warming potential;

- ILCD: The International Life cycle Data System;

- IPCC: Intergovernmental Panel on Climate Change;

- ISO: International Organisation for Standardisation;

- LCA: Life cycle assessment;

- LCl: Life cycle inventory;

- LCIA: Life cycle impact assessment;

- PAS: Publicly Available Specification;

- PEF: Product environmental footprint;

- PEFCR: Product environmental footprint category rules;

- PCR: Product category rules;

- TR: Technical report;

- TS: Technical Specification.

\section{Acknowledgements}

The authors acknowledge COST Action FP1407 in supporting networking activities that resulted in the cooperation behind this publication. Also specifically for supporting a Short Scientific Mission (STSM) with reference code COST-STSM-ECOSTSTSM-FP1407-020117-081905 where a large part of this work was performed. Ana Dias acknowledges the project Sustainfor (PTDC/AGR-FOR/1510/2014) funded under the project 3599-PPCDT by FCT (Science and Technology Foundation, Portugal) and by FEDER (European Regional Development Fund). Edwin Zea acknowledges the Chair of Sustainable Construction ETHZ for their support. Callum Hill acknowledges the European Commission Horizon 2020 project ISOBIO (project no. 636835) for financial support.

\section{References}

Archila-Santos HF, Ansell MP, Walker P (2012). Low carbon construction using guadua bamboo in Colombia. Key Engineering Materials 517: 127-134. - doi: 10.4028/www.scientific.net/ KEM.517.127

Arfvidsson J, De Angelis E, Dodoo A, Dolezal F, Gustavsson L, Hafner A, Häkkinen T, Kuittinen $M$, Linkosalmi L, Ludvig A, Tinkhof OM, Mötzl $H$, Mundt-Petersen SO, Ott S, Peñaloza D, Pittau F, Sathre R, Spitzbart C, Takano A, Toratti T, Valtonen T, Vares S, Weiss G, Winter S, Zanata $\mathrm{G}$, Arfvidsson J (2013). Wood in carbon efficient construction - Tools, methods and applications (Kuittinen M, Ludvig A, Weiss G eds). CEl-Bois, Brussels, Belgium, pp. 163. [online] URL: http:// lup.lub.lu.se/search/publication/a602b17808eo-486a-ae3c-9afdcfe4e05f

Bolwig S, Gibbon P (2009). Counting carbon in the marketplace. part I - Overview paper. Global forum on trade - trade and climate change. The Organisation for Economic Co- operation and Development, Paris, France, pp. 41.

Brandão M, Levasseur A, Kirschbaum MUF, Weidema BP, Cowie AL, Jorgensen SV, Hauschild $M Z$, Pennington DW, Chomkhamsri K (2013). Key issues and options in accounting for carbon sequestration and temporary storage in life cycle assessment and carbon footprinting. The International Journal of Life Cycle Assessment 18: 230-240. - doi: 10.1007/s11367-012-0451-

CEN/TR-16970 (2016). Sustainability of construction works - Guidance for the implementation of EN 15804. CEN/TR 16970:2016, European Committee for Standardization, Brussels, Belgium, pp. 27.

Cherubini F, Peters GP, Berntsen T, Stromman $\mathrm{AH}$, Hertwich $\mathrm{E}$ (2011). $\mathrm{CO}_{2}$ emissions from biomass combustion for bioenergy: atmospheric decay and contribution to global warming. GCB Bioenergy 3: 413-426. - doi: 10.1111/j.1757-1707. 2011.01102.x

Cochran I (2016). Six lessons on carbon accounting for Article 6 of the Paris Agreement. Institute for Climate Economics, Paris, Climate Brief 41: 1-6.

De Rosa M, Schmidt J, Brandão M, Pizzol M (2016). A flexible parametric model for a balanced account of forest carbon fluxes in LCA. The International Journal of Life Cycle Assessment 22 (2): 1-13.

De Schryver A, Galatola M, Schau EM, Benini L, Pant R (2016). Guidance and requirements for biogenic carbon modelling in PEFCRs (version 2.2). European Commission, Brussels, Belgium, pp. 1-7.

Downie A, Lau D, Cowie A, Munroe P (2014). Approaches to greenhouse gas accounting methods for biomass carbon. Biomass and Bioenergy 60: 18-31. - doi: 10.1016/j.biombioe.20 13.11.009

EN-15804 (2012). Sustainability of construction works. Environmental product declarations. Core rules for the product category of construction products. EN 15804:2012, European Committee for Standardization, Brussels, Belgium, pp. 49.

EN-15804 (2013). Sustainability of construction works. Environmental product declarations. Core rules for the product category of construction products. EN 15804:2012+A12013, European Committee for Standardization, Brussels, Belgium, pp. 66.

EN-16449 (2014). Wood and wood-based products - Calculation of the biogenic carbon content of wood and conversion to carbon dioxide. EN 16449:2014, European Committee for Standardization, Brussels, Belgium, pp. 8.

EN-16485 (2014). Round and sawn timber - Environmental Product Declarations - Product category rules for wood and wood-based products for use in construction. European Committee for Standardization, Brussels, Belgium, pp. 32.

EU (2010). Regulation (EU) no. 995/2010 of the European Parliament and of the Council of 20 October 2010 laying down the obligations of operators who place timber and timber products on the market. Official Journal of the European Union L295: 23-34. - doi: 10.1017/CBO97 81107415324.004

European Commission (2010). International Ref- erence Life Cycle Data System (ILCD): handbook - general guide for life cycle assessment detailed guidance (Joint Research Centre Institute for Environment and Sustainability ed). Publications Office of the European Union, Luxembourg, pp. 417.

Fearnside PM, Lashof DA, Moura-Costa P (2000). Accounting for time in mitigating global warming through land-use change and forestry. Mitigation and Adaptation Strategies for Global Change 5: 239-270. - doi: 10.1023/A:1009625122 628

Fouquet M, Levasseur A, Margni M, Lebert A, Lasvaux S, Souyri B, Buhé C, Woloszyn M (2015). Methodological challenges and developments in LCA of low energy buildings: application to biogenic carbon and global warming assessment. Building and Environment 90: 5159. - doi: 10.1016/j.buildenv.2015.03.022 Guest G, Bright RM, Cherubini F, Stromman AH (2013a). Consistent quantification of climate impacts due to biogenic carbon storage across a range of bio-product systems. Environmental Impact Assessment Review 43: 21-30. - doi: 10.1016/j.eiar.2013.05.002

Guest G, Cherubini F, Stromman AH (2013b). Global warming potential of carbon dioxide emissions from biomass stored in the anthroposphere and used for bioenergy at end of life. Journal of Industrial Ecology 17: 20-30. - doi: 10.1111/j.1530-9290.2012.00507.x

Gustavsson L, Pingoud K, Sathre R (2006). Carbon dioxide balance of wood substitution: comparing concrete- and wood-framed buildings. Mitigation and Adaptation Strategies for Global Change 11: 667-691. - doi: 10.1007/s110270o6-7207-1

Helin T, Sokka L, Soimakallio S, Pingoud K, Pajula $T$ (2013). Approaches for inclusion of forest carbon cycle in life cycle assessment - a review. GCB Bioenergy 5: 475-486. - doi: 10.1111/gcbb. 12016

Herzog H, Caldeira K, Reilly J (2003). An issue of permanence: assessing the effectiveness of temporary carbon storage. Climatic Change 59: 293-310. - doi: 10.1023/A:1024801618900 IPCC (2014). 2013 Revised supplementary methods and good practice guidance arising from the Kyoto Protocol. Intergovernmental Panel on Climate Change, Geneva, Switzerland, pp. 268.

ISO-14025 (2010). Environmental levels and declarations - Type III environmental declarations Principles and procedures. International Organization for Standardization, Geneva, Switzerland, pp. 36.

ISO-21930 (2007). Sustainability in building construction - Environmental declaration of building products. International Organization for Standardization, Geneva, Switzerland, pp 26.

ISO/DIS-21930 (2015). Sustainability in buildings and civil engineering works - Environmental declaration of building products (Draft version). International Organization for Standardization, Geneva, Switzerland, pp 93.

ISO/TS-14067 (2013). Greenhouse gases - Carbon footprint of products - Requirements and guidelines for quantification and communication. International Organization for Standardization, Geneva, Switzerland, pp. 52.

Klein D, Wolf C, Schulz C, Weber-Blaschke G 
(2015). 20 years of life cycle assessment (LCA) in the forestry sector: state of the art and a methodical proposal for the LCA of forest production. The International Journal of Life Cycle Assessment 20: 556-575. - doi: 10.1007/s11367015-0847-1

Levasseur A, Lesage $P$, Margni $M$, Deschênes $L$, Samson R (2010). Considering time in LCA: dynamic LCA and its application to global warming impact assessments. Environmental Science and Technology 44: 3169-3174. - doi: 10.1021/es 9030003

Levasseur A, Lesage $P$, Margni $M$, Samson $R$ (2013). Biogenic carbon and temporary storage addressed with dynamic life cycle assessment. Journal of Industrial Ecology 17: 117-128. - doi: 10.1111/j.1530-9290.2012.00503.x

Lippke B, Oneil E, Harrison R, Skog K, Gustavsson L, Sathre R (2011). Life cycle impacts of forest management and wood utilization on carbon mitigation: knowns and unknowns. Carbon Management 2: 303-333. - doi: 10.4155/cmt.11.24 Masera OR, Garza-Caligaris JF, Kanninen M, Karjalainen T, Liski J, Nabuurs GJ, Pussinen A, De Jong BHJ, Mohren GMJ (2003). Modeling carbon sequestration in afforestation, agroforestry and forest management projects: the CO2FIX V. 2 approach. Ecological Modelling 164: 177-199. - doi: 10.1016/S0304-3800(02)00419-2

McKechnie J, Colombo S, Chen J, Mabee W, MacLean HL (2011). Forest bioenergy or forest carbon? Assessing trade-offs in greenhouse gas mitigation with wood-based fuels. Environmental Science and Technology 45: 789-795. - doi: 10.1021/es1024004

Minkov N, Schneider L, Lehmann A, Finkbeiner $M$ (2015). Type III environmental declaration programmes and harmonization of product category rules: status quo and practical challenges. Journal of Cleaner Production 94: 235246. - doi: 10.1016/j.jclepro.2015.02.012

Moura Costa P, Wilson C (2000). An equivalence factor between $\mathrm{CO}_{2}$ avoided emissions and sequestration - description and applications in forestry. Mitigation and Adaptation Strategies for Global Change 5: 51-60. - doi: 10.1023/A:100 9697625521

Muñoz I, Schmidt JH (2016). Methane oxidation, biogenic carbon, and the IPCC's emission metrics. Proposal for a consistent greenhouse-gas accounting. The International Journal of Life Cycle Assessment 21: 1069-1075. - doi: 10.1007/ s11367-016-1091-z

Nordby AS, Solli C, Dahlstrm O (2015). Helhetlig miljøvurdering av byggematerialer [Holistic environmental assessment of building materials]. Project report, Asplan Viak, Trondheim, Norway, pp. 77. [in Norwegian]

PAS-2050 (2008). PAS 2050 - Specification for the assessment of the life cycle greenhouse gas emissions of goods and services. British Standards Institution, London, UK, pp. 54.

PAS-2050 (2011). PAS 2050:2011 Specification for the assessment of the life cycle greenhouse gas emissions of goods and services. British Standards Institution, London, UK, pp. 45.

Peñaloza D, Erlandsson M, Falk A (2016). Exploring the climate impact effects of increased use of bio-based materials in buildings. Construction and Building Materials 125: 219-226. - doi: 10.1016/j.conbuildmat.2016.08.041

PRé Consultants (2016). SimaPro Database Manual - Methods Library. PRé Consultants, Amersfoort, Netherlands, pp. 63.

Richards KR (1997). The time value of carbon in bottom-up studies. Critical Reviews in Environ- mental Science and Technology 27: 279-292. doi: 10.1080/10643389709388526

Røyne F, Peñaloza D, Sandin G, Berlin J, Svanström M (2016). Climate impact assessment in life cycle assessments of forest products: implications of method choice for results and decision-making. Journal of Cleaner Production 116: 90-99. - doi: 10.1016/j.jclepro.2016.01.009

Sandin G, Peters GM, Svanström M (2016). LCA of forest products - challenges and solutions. Springer International Publishing, pp. 25-67. doi: 10.1007/978-3-319-44027-9_4

Stechemesser K, Guenther E (2012). Carbon accounting: a systematic literature review. Journal of Cleaner Production 36: 17-38. - doi: 10.101 6/j.jclepro.2012.02.021

Tellnes LGF, Gobakken LR, Flaete PO, Alfredsen $G$ (2014). Carbon footprint including effect of carbon storage for selected wooden facade materials. Wood Material Science and Engineering 9: 139-143. - doi: 10.1080/17480272.20 14.904432

UL-IES (2012). CML-IA characterisation factors Software and data - CML. Web site. [online] URL: http://cml.leiden.edu/software/data-cmlia. html\#downloads

Vogtländer JG, Van Der Velden NM, Van Der Lugt $P$ (2014). Carbon sequestration in LCA, a proposal for a new approach based on the global carbon cycle; cases on wood and on bamboo. The International Journal of Life Cycle Assessment 19: 13-23. - doi: 10.1007/s11367-013-0629-6 Zea Escamilla E, Habert G, Wohlmuth E (2016). When $\mathrm{CO}_{2}$ counts: sustainability assessment of industrialized bamboo as an alternative for social housing programs in the Philippines. Building and Environment 103: 44-53. - doi: 10.1016/j.buildenv.2016.04.003 